\title{
Diagnosis of bladder cancer by immunocytochemical detection of minichromosome maintenance protein-2 in cells retrieved
} from urine

\begin{abstract}
K Saeb-Parsy', A Wilson ${ }^{2}$, C Scarpini ${ }^{3}$, M Corcoran', S Chilcott ${ }^{4}$, M McKean ${ }^{5}$, B Thottakam ${ }^{6}$, B Rai ${ }^{7}$, G Nabi $^{8}$, D Rana', M Perera', K Stewart ${ }^{10}$, RA Laskey' ', DE Neal' and N Coleman ${ }^{*, 3}$

'Department of Urology, Addenbrooke's Hospital, Cambridge, UK; ${ }^{2}$ Department of Computing, Robert Gordon University, Aberdeen, UK; ${ }^{3}$ Department of Pathology, University of Cambridge, Cambridge, UK; ${ }^{4}$ Diagnostic Cytology, Department of Histopathology, Addenbrooke's Hospital, Cambridge, UK; ${ }^{5}$ Department of Pathology, Aberdeen Royal Infirmary, Aberdeen, UK; ${ }^{6}$ Cytosystems Ltd, Aberdeen, UK; ${ }^{7}$ Department of Urology, Aberdeen Royal Infirmary, Aberdeen, UK; ${ }^{8}$ Population Sciences Division, Department of Urology, Medical Research Institute, University of Dundee, Dundee, UK; ${ }^{9}$ Department of Cytopathology, Manchester Royal Infirmary, Manchester, UK; ${ }^{10}$ Division of Applied Medicine, University of Aberdeen, School of Medicine and Dentistry, Aberdeen, UK; "Department of Zoology, University of Cambridge, Cambridge, UK
\end{abstract}

BACKGROUND: We tested the accuracy of immunocytochemistry (ICC) for minichromosome maintenance protein-2 (MCM-2) in diagnosing bladder cancer, using cells retrieved from urine.

METHODS: Adequate samples were obtained from 497 patients, the majority presenting with gross haematuria $(\mathrm{GH})$ or undergoing cystoscopic surveillance (CS) following previous bladder cancer. We performed an initial study of 313 patients, followed by a validation study of 184 patients. In all cases, presence/absence of bladder cancer was established by cystoscopy/biopsy.

RESULTS: In the initial study, receiver operator characteristic analysis showed an area under the curve of $0.820(P<0.0005)$ for the GH group and $0.821 \quad(P<0.01)$ for the CS group. Optimal sensitivity/specificity were provided by threshold values of $50+M C M-2-$ positive cells in $\mathrm{GH}$ samples and $200+$ cells in CS samples, based on a minimum total cell number of 5000. Applying these thresholds to the validation data set gave $81.3 \%$ sensitivity, $76.0 \%$ specificity and $92.7 \%$ negative predictive value (NPV) in GH and 63.2\% sensitivity, $89.9 \%$ specificity and $89.9 \%$ NPV in CS. Minichromosome maintenance protein-2 ICC provided clinically relevant improvements over urine cytology, with greater sensitivity in $\mathrm{GH}$ and greater specificity in $\mathrm{CS}(P=0.05)$.

CONCLUSIONS: Minichromosome maintenance protein-2 ICC is a reproducible and accurate test that is suitable for both GH and CS patient groups.

British Journal of Cancer (2012) I 07, |384-139|. doi:I0.1038/bjc.2012.38 I www.bjcancer.com

Published online II September 2012

(c) 2012 Cancer Research UK

Keywords: bladder cancer; urothelial carcinoma; MCM-2; cytology; immunocytochemistry; biomarker

Most patients with bladder cancer present with either gross haematuria $(\mathrm{GH})$ or microscopic haematuria $(\mathrm{MH})$ (Rodgers et al, 2006). The majority of bladder cancers are superficial, non-muscleinvasive tumours with a good prognosis. However, over two thirds of such cases recur, of which $10-30 \%$ progress to muscle-invasive disease (Heney et al, 1983; Rubben et al, 1988; Pagano et al, 1991; Prout et al, 1992). This has led to the development of surveillance programmes, in order to limit the morbidity and mortality associated with recurrent disease. Currently accepted investigations for surveillance include cystoscopy with urinary cytology (Halling and Kipp, 2008), as well as imaging of the upper urinary tract.

The reported sensitivity of urine cytology for high-grade bladder cancer and carcinoma in situ (CIS) varies from $38-84 \%$, with a reported specificity of $83-99.7 \%$ (Lotan and Roehrborn, 2003). Although it is cheap and non-invasive, the lowest sensitivity of cytology is in detecting the commonest bladder cancers, which are superficial low-grade tumours (Karakiewicz et al, 2006).

*Correspondence: Professor N Coleman; E-mail: nc109@cam.ac.uk Received 23 March 2012; revised 30 July 2012; accepted 2 August 2012; published online II September 2012
Cystoscopy is the gold standard investigation but has falsenegative rates of $10-40 \%$, either from operator error or from small areas of CIS, which may be difficult to detect (Herr, 1999; van der Poel and Debruyne, 2001; Hwang et al, 2011). Furthermore, cystoscopy is associated with potential side effects and may cause discomfort and distress to the patient. Current follow-up protocols after the initial diagnosis of bladder cancer typically include regular flexible cystoscopy and urine cytology, performed as often as every three months for 1-3 years and every 6 months for 2-3 years thereafter, depending on tumour characteristics. Annual follow-up is often then undertaken, assuming no recurrence of tumour.

In view of the clinical burden and cost associated with surveillance of non-muscle-invasive bladder cancer, there is an increasing drive to identify more reliable urinary biomarkers. Non-invasive biomarkers could be useful both for screening highrisk populations and monitoring patients with a history of bladder cancer. This may help identify early recurrence and hence prevent disease progression. Thus, a reliable urine marker has the potential to replace or complement cystoscopy for both the initial diagnosis of bladder cancer and for future surveillance. 
At least 14 such biomarkers have so far been described, 6 of which have received approval from the United States Food and Drug Administration (Herman et al, 2008). However, none meets all the criteria of an ideal tumour biomarker. Indeed, non-invasive tumour markers in general have sensitivity for bladder cancer equal to or only slightly greater than that of cytology, even in highgrade cancers.

Since the late 1990s, there has been interest in developing screening tests for epithelial cancers, based on minichromosome maintenance (MCM) proteins as biomarkers (Williams et al, 1998; Freeman et al, 1999; Stoeber et al, 1999; Davies et al, 2002; Sirieix et al, 2003; Baldwin et al, 2003; Chatrath et al, 2003). Minichromosome maintenance proteins 2-7 are essential for DNA replication in all eukaryotic cells and for restricting replication to once per cell cycle (Kearsey and Labib, 1998; Gonzalez et al, 2005). These proteins, which are abundant throughout the cell cycle (Kearsey et al, 1996; Maiorano et al, 1996), are downregulated following cell cycle exit by quiescence, differentiation or senescence (Musahl et al, 1998; Madine et al, 2000; Stoeber et al, 2001).

The application of MCMs to detecting bladder cancer is based on the fact that most cells in the human body, including urothelial cells, are not cycling and exist in a state of quiescence (G0 phase). Although MCMs are normally restricted to the basal proliferative compartments of epithelia, ectopic expression is a characteristic feature of malignancy and pre-malignancy. Indeed, MCM expression is often seen in all epithelial layers, including the superficial cells (Gonzalez et al, 2005; Scarpini et al, 2008). This is the case for bladder cancer, where a high frequency of MCM-positive cells correlates with adverse clinical outcome (Korkolopoulou et al, 2005).

In the bladder, surface cells are exfoliated into the urine. Immunocytochemical staining for MCMs should therefore allow discrimination between immuno-positive abnormal cells and their immuno-negative normal counterparts. Early work suggested that MCMs could be detected using liquid-phase assays performed on homogenised urinary sediments (Stoeber et al, 1999) and the clinical performance of this approach was subsequently assessed using 353 urine samples (Stoeber et al, 2002). An alternative approach, which may find greater favour among practising cytopathologists, is to detect MCMs in urine-derived epithelial cells by immunocytochemistry (ICC). This commonly-used technique preserves cell morphology and allows cytological verification of cellular abnormalities, based on the haematoxylin counterstain.

Here, we report the findings of a study of bladder cancer detection using immunocytochemical staining for MCM-2 in cells retrieved from urine. We studied 497 patients referred for investigation of possible bladder cancer, either presenting with GH or $\mathrm{MH}$, together with patients with a known history of bladder cancer who were on cystoscopic surveillance (CS) as part of their routine clinical care. Our data show that MCM-2 ICC is a reproducible and accurate diagnostic test that warrants larger-scale application.

\section{MATERIALS AND METHODS}

\section{Study subjects}

Patients attending urology clinics at two centres in the UK were recruited into the study. The first was Aberdeen Royal Infirmary, where the initial phase of the study evaluating the practicality of using urinary MCM-2 ICC for detecting bladder cancer was carried out. The second was Addenbrooke's Hospital, Cambridge, where we validated and extended the findings of the Aberdeen study. All patients gave written consent before being recruited. Local Research Ethics Committee approval was granted for each institution (Aberdeen Ref. 07/SO802/136; Cambridge Ref. 03/018).
All urine samples used to analyse test accuracy were from patients in whom the presence or absence of bladder cancer was ascertained by cystoscopy and biopsy. In all cases, the relevant tissue diagnosis was made by a member of the team of consultant urological histopathologists at the participating centre.

\section{Pilot phase (Aberdeen)}

Fifty-six of 74 patients with established bladder cancer who were invited, agreed to participate in the pilot work. A total of 154 urine samples were collected from these 56 participants. The pilot work was aimed at optimising: (i) timing of urine sample collection; (ii) storage and processing conditions for generating liquid-based cytology (LBC) samples; (iii) urine sample volume; and (iv) slide storage conditions that preserved intact bladder epithelial cells over 3 months.

The work confirmed that early morning urine samples were of poor quality and that the best time for obtaining samples was between 1100 and 1600 hours (data not shown). All samples required processing within $4 \mathrm{~h}$ of voiding. Under these conditions, $50 \mathrm{ml}$ urine aliquots from whole-volume urine voids produced adequate numbers of bladder epithelial cells in all samples collected (data not shown). Cells remained intact for over 3 months on LBC slides sprayed with Surgipath (Surgipath Medical Inc., Richmond, IL, USA) and stored in the dark at $4{ }^{\circ} \mathrm{C}$ (data not shown).

\section{Initial study (Aberdeen)}

In the initial study at Aberdeen Royal Infirmary, urine samples (regardless of adequacy) were obtained from a total of 317 patients, recruited from the $\mathrm{GH}$ (170 patients) or follow-up CS clinics (147 patients). There were 26 individuals with bladder cancer in these patient groups. In addition, 51 patients presenting with $\mathrm{MH}$ were investigated (none with bladder cancer). A further 50 urines were collected from normal control subjects with no clinical evidence of urinary tract pathology. Further details are given in Table 1. No positive selection criteria were applied, although patients with other urinary tract pathology, catheter in situ and evidence of secondary spread of bladder cancer were excluded. A fresh wholevolume urine void was collected from each participant. Samples were transferred to the cytopathology laboratory for analysis within $4 \mathrm{~h}$ from the time of void.

\section{Validation study (Cambridge)}

In total, urine samples (regardless of adequacy) were obtained from 249 patients at the Urology Outpatient Clinic, Addenbrooke's Hospital, Cambridge. No positive selection criteria were applied, with exclusion criteria being as for the initial study (Aberdeen). Of the 249 patients, 89 presented with GH, 44 with $\mathrm{MH}$ and 116 were undergoing CS for bladder cancer. Full details are given in Table 2. All samples were prepared and stained using the methodology determined from the Aberdeen studies (see below). Two LBC slides were made, one for routine Papanicolaou (PAP) staining using the conventional method and a second for MCM-2 ICC, which was performed at a separate commercial laboratory (Quest Laboratories, London, UK). The immuno-stained slides, together with the PAP-stained slide for each patient, were thereafter transferred to the Manchester Royal Infirmary and reviewed independently by two senior cytopathologists (DR and MP).

\section{Preparation of LBC slides from urine samples}

Specimens were decanted into $50 \mathrm{ml}$ Falcon tubes at the cytopathology laboratory and centrifuged at 2500 r.p.m. for $10 \mathrm{~min}$. Two cell pellets were pooled by washing with Cytolyt (Hologic UK, Crawley, UK). The pooled sample was then 
Table I Summary of patient details and results for the initial study (Aberdeen)

\begin{tabular}{|c|c|c|c|c|}
\hline & GH & CS & MH & Contro \\
\hline $\begin{array}{l}\text { Median age } \\
\text { (Range) }\end{array}$ & $\begin{array}{c}64 \\
(19-90)\end{array}$ & $\begin{array}{c}73 \\
(32-90)\end{array}$ & $\begin{array}{c}61.5 \\
(21-87)\end{array}$ & $\begin{array}{c}34 \\
(20-64)\end{array}$ \\
\hline $\begin{array}{l}\text { Male } \\
(\%)\end{array}$ & $\begin{array}{l}115 \\
(68)\end{array}$ & $\begin{array}{l}108 \\
(74)\end{array}$ & $\begin{array}{l}21 \\
(4 I)\end{array}$ & $\begin{array}{l}21 \\
(42)\end{array}$ \\
\hline $\begin{array}{l}\text { Female } \\
(\%)\end{array}$ & $\begin{array}{c}55 \\
(32)\end{array}$ & $\begin{array}{l}39 \\
(26)\end{array}$ & $\begin{array}{l}30 \\
(59)\end{array}$ & $\begin{array}{l}29 \\
(58)\end{array}$ \\
\hline $\begin{array}{l}\text { Total } \\
(\%)\end{array}$ & $\begin{array}{c}170 \\
(100)\end{array}$ & $\begin{array}{l}147 \\
(100)\end{array}$ & $\begin{array}{c}51 \\
(100)\end{array}$ & $\begin{array}{l}50 \\
(100)\end{array}$ \\
\hline $\begin{array}{l}\text { No of bladder cancer } \\
(\%)\end{array}$ & $\begin{array}{c}21 \\
(17.9)\end{array}$ & $\begin{array}{c}5 \\
(4.5)\end{array}$ & 0 & 0 \\
\hline \multicolumn{5}{|l|}{ MCM-2 } \\
\hline $\begin{array}{l}\text { No of adequate samples } \\
(\%)\end{array}$ & $\begin{array}{c}117 \\
(68.8)\end{array}$ & $\begin{array}{c}112 \\
(76.2)\end{array}$ & $\begin{array}{c}42 \\
(82.4)\end{array}$ & $\begin{array}{c}42 \\
(84.0)\end{array}$ \\
\hline $\begin{array}{l}\text { Sensitivity } \\
(95 \% \mathrm{Cl})\end{array}$ & $\begin{array}{c}85.7 \% \\
(63.7,97.0)\end{array}$ & $\begin{array}{c}60.0 \% \\
(14.6,94.7)\end{array}$ & & \\
\hline $\begin{array}{l}\text { Specificity } \\
(95 \% \mathrm{Cl})\end{array}$ & $\begin{array}{c}52.1 \% \\
(41.6,62.4)\end{array}$ & $\begin{array}{c}79.4 \% \\
(70.5,86.6)\end{array}$ & & \\
\hline NPV & $94.3 \%$ & $97.7 \%$ & & \\
\hline \multicolumn{5}{|l|}{ Cytology } \\
\hline $\begin{array}{l}\text { No of adequate samples } \\
(\%)\end{array}$ & $\begin{array}{c}117 \\
(68.8)\end{array}$ & $\begin{array}{c}113 \\
(76.9)\end{array}$ & & \\
\hline $\begin{array}{l}\text { Sensitivity } \\
(95 \% \mathrm{Cl})\end{array}$ & $\begin{array}{c}71.4 \% \\
(47.8,88.7)\end{array}$ & $\begin{array}{c}40 \% \\
(5.3,85.3)\end{array}$ & & \\
\hline $\begin{array}{l}\text { Specificity } \\
(95 \% \mathrm{Cl})\end{array}$ & $\begin{array}{c}88.5 \% * \\
(80.4,94.1)\end{array}$ & $\begin{array}{c}72.2 \% \\
(62.8,80.4)\end{array}$ & & \\
\hline NPV & $96.6 \%$ & $98.7 \%$ & & \\
\hline \multicolumn{5}{|l|}{ MCM-2/cytology } \\
\hline $\begin{array}{l}\text { No of adequate samples } \\
(\%)\end{array}$ & $\begin{array}{c}118 \\
(69.4)\end{array}$ & $\begin{array}{c}113 \\
(76.9)\end{array}$ & & \\
\hline $\begin{array}{l}\text { Sensitivity } \\
(95 \% \mathrm{Cl})\end{array}$ & $\begin{array}{c}86.4 \% \\
(65.1,97.1)\end{array}$ & $\begin{array}{c}60.0 \% \\
(14.7,94.7)\end{array}$ & & \\
\hline $\begin{array}{l}\text { Specificity } \\
(95 \% \mathrm{Cl})\end{array}$ & $\begin{array}{c}52.1 \% \\
(41.6,62.4)\end{array}$ & $\begin{array}{c}76.9 \% \\
(67.8,84.4)\end{array}$ & & \\
\hline NPV & $94.3 \%$ & $97.6 \%$ & & \\
\hline
\end{tabular}

Abbreviations: $\mathrm{Cl}$, confidence interval; $\mathrm{CS}$, cystoscopic surveillance; $\mathrm{GH}$, gross haematuria; MCM-2, minichromosome maintenance protein-2; $\mathrm{MH}$, microscopic haematuria; NPV, negative predictive value. The threshold number of MCM-2positive cells was 50 for the $\mathrm{GH}$ group and 200 for the CS group. For all adequate samples, the presence or absence of bladder cancer was established by cystoscopy/ biopsy. The combined MCM-2/cytology test was considered positive if either of the individual tests was positive. $* P<0.005$ for $M C M-2$ testing vs urine cytology.

re-centrifuged and the cell pellet re-suspended and split equally between two PreservCyt vials (Hologic, UK), one for conventional PAP staining and one for MCM-2 ICC. Thin layer slides were prepared using a standard Thinprep 2000 processor (Hologic UK).

Papanicolaou staining was undertaken following the standard clinical diagnostic method and the slides assessed for cellularity and malignancy by the lead consultant cytopathologists (MM, DR, MP). Slides for ICC assessment were spray fixed with Surgipath (Surgipath Medical Inc.) and stored at $4{ }^{\circ} \mathrm{C}$ until stained.

Table 2 Summary of patient details and results for the validation study (Cambridge)

\begin{tabular}{lccc}
\hline & GH & CS & MH \\
\hline $\begin{array}{l}\text { Median age } \\
\text { (Range) }\end{array}$ & 65 & 71 & 60 \\
$(22-87)$ & $(48-89)$ & $(37-82)$
\end{tabular}

Male

(\%)

Female

(\%)

Total

(\%)

No of bladder cancer

(\%)

MCM-2

\begin{tabular}{|c|c|c|}
\hline $\begin{array}{l}\text { No of adequate samples } \\
(\%)\end{array}$ & $\begin{array}{c}66 \\
(74.2)\end{array}$ & $\begin{array}{c}88 \\
(75.9)\end{array}$ \\
\hline $\begin{array}{l}\text { Sensitivity } \\
(95 \% \mathrm{Cl})\end{array}$ & $\begin{array}{c}81.3 \% \\
(54.4,96.0)\end{array}$ & $\begin{array}{c}63.2 \% \\
(38.4,83.7)\end{array}$ \\
\hline $\begin{array}{l}\text { Specificity } \\
(95 \% \mathrm{Cl})\end{array}$ & $\begin{array}{c}76.0 \% \\
(61.8,86.9)\end{array}$ & $\begin{array}{c}89.9 \% \\
(80.2,95.8)\end{array}$ \\
\hline NPV & $92.7 \%$ & $89.9 \%$ \\
\hline tology & & \\
\hline $\begin{array}{l}\text { No of adequate samples } \\
(\%)\end{array}$ & $\begin{array}{c}66 \\
(74.2)\end{array}$ & $\begin{array}{c}88 \\
(75.9)\end{array}$ \\
\hline $\begin{array}{l}\text { Sensitivity } \\
(95 \% \mathrm{Cl})\end{array}$ & $\begin{array}{c}62.5 \% \\
(35.4,84.8)\end{array}$ & $\begin{array}{c}55.0 \% \\
(31.5,76.9)\end{array}$ \\
\hline $\begin{array}{l}\text { Specificity } \\
(95 \% \mathrm{Cl})\end{array}$ & $\begin{array}{c}75.5 \% \\
(61.1,86.7)\end{array}$ & $\begin{array}{c}77.9 \% * \\
(66.2,87.1)\end{array}$ \\
\hline NPV & $90.2 \%$ & $88.3 \%$ \\
\hline $\begin{array}{l}\text { 1CM-2/cytology } \\
\text { No of adequate samples } \\
(\%)\end{array}$ & $\begin{array}{c}66 \\
(74.2)\end{array}$ & $\begin{array}{c}89 \\
(76.7)\end{array}$ \\
\hline $\begin{array}{l}\text { Sensitivity } \\
(95 \% \mathrm{Cl})\end{array}$ & $\begin{array}{c}81.3 \% \\
(54.4,96.0)\end{array}$ & $\begin{array}{c}65.0 \% \\
(40.8,84.6)\end{array}$ \\
\hline $\begin{array}{l}\text { Specificity } \\
(95 \% \mathrm{Cl})\end{array}$ & $\begin{array}{c}76.0 \% \\
(61.8,86.9)\end{array}$ & $\begin{array}{c}88.4 \% \\
(78.4,94.9)\end{array}$ \\
\hline NPV & $92.7 \%$ & $89.7 \%$ \\
\hline
\end{tabular}

Abbreviations: $\mathrm{Cl}$, confidence interval; $\mathrm{CS}$, cystoscopic surveillance; $\mathrm{GH}$, gross haematuria; MCM-2, minichromosome maintenance protein-2; $M H$, microscopic haematuria; NPV, negative predictive value. The threshold number of MCM-2positive cells was 50 for the $\mathrm{GH}$ group and 200 for the $\mathrm{CS}$ group. For all adequate samples, the presence or absence of bladder cancer was established by cystoscopy/ biopsy. The combined MCM-2/cytology test was considered positive if either of the individual tests was positive. ${ }^{*} P<0.05$ for MCM-2 testing vs urine cytology.

\section{Immunocytochemical staining for MCM-2}

Immunocytochemistry was performed using a standard biotin-free Dako REAL Envision detection system (K5007) staining method, using 3,3'-diaminobenzidine (DAB) as the chromogen, on an automated Dako Flat Bed-Stainer (Dako, Ely, UK).

The thin layer slides were incubated in $50 \%$ ethanol for $5 \mathrm{~min}$ then rinsed in water before antigen retrieval. The antigen retrieval step consisted of heating the slides in EDTA buffer ( $\mathrm{pH}$ 7.8) at 
$95^{\circ} \mathrm{C}$ for $45 \mathrm{~min}$. The sections were then allowed to cool to room temperature before being placed in the automated stainer. Slides were incubated for $5 \mathrm{~min}$ with hydrogen peroxide solution (Dako REAL S2023), to block endogenous peroxidase, then rinsed three times in Dako REAL wash buffer (S3006). Primary antibody MCM-2 (Scarpini et al, 2008), diluted 1:40 in antibody diluent (Dako REAL S2022), was applied for $60 \mathrm{~min}$ at room temperature before being rinsed twice with wash buffer.

Pre-diluted peroxidase-polymer labelled goat anti-mouse/rabbit secondary antibody detection reagent (Envision, Dako) was applied for $30 \mathrm{~min}$ at room temperature, followed by a further wash with buffer. Sites of peroxidase activity were then demonstrated with $\mathrm{DAB}$, applied for two successive 5 min periods. After a rinse in water, slides were immersed in $0.5 \%$ copper sulphate in saline stain enhancer for $5 \mathrm{~min}$. Following this, slides were lightly counterstained in haematoxylin for $10 \mathrm{~s}$ then rinsed in tap water before being 'blued' in Scott's tap water substitute for $40 \mathrm{~s}$. Slides were then rinsed in water, dehydrated through graded alcohols to xylene and cover slipped using mounting media.

The bladder cancer cell line EJ28 acted as a positive control for MCM-2 staining. A duplicate negative control slide was run in parallel, where the primary antibody was replaced by non-immune mouse immunoglobulin (Dako Universal negative mouse control N1695). The presence of MCM-2-positive staining of urothelial cells in the cytology samples was assessed by the lead consultant cytopathologist at Aberdeen Royal Infirmary (MM), who was blinded to all clinical information. Representative images of EJ28 cells and a clinical sample are shown in Figure 1.

\section{Slide Review}

Cytology assessment The PAP-stained slides were examined to provide a diagnosis based on cell morphology. Four diagnostic categories were used, based on conventional terminology for routine reporting of cytological specimens. The 'atypical' and 'suspicious' categories were combined and graded as 'indeterminate'. The other categories used were 'benign' and 'malignant'. For consistency with the ICC evaluation (see Results), a slide with a cell count of fewer than 5000 urothelial cells was deemed inadequate, unless the cells appeared malignant. Samples were also assessed using a combination of cytology and MCM-2 ICC (see below) and considered positive if either of the individual tests was positive.

Immunocytochemistry assessment Each slide was examined to determine the total cell count and the number of MCM-2-positive nuclei. A semi-quantitative total cell count was performed by examining 10 high power fields (HPF; $\times 40$ objective lens) selected at random from within the standard circular cell monolayer generated by the Thinprep 2000 processor. The area of the monolayer (always $20 \mathrm{~mm}^{2}$ ) was divided by the area of an HPF, to determine the number of HPFs per monolayer. The multiplication factor for the microscope used in Aberdeen was 1072 but for simplification 1000 was applied. This value was then multiplied by the average number of cells per HPF, to determine the number of cells per monolayer (slide). The same multiplication principle was also used for the microscope in Manchester (where slides from Cambridge study were evaluated). If the number of cells per HPF was $>5$, the total cell count values derived were rounded into categories, as follows: (i) Slides with 5-7 cells per HPF were denoted to contain 5000 cells in total; (ii) slides with 8-12 cells per HPF were denoted to contain 10000 cells; (iii) slides with 13-17 cells per HPF were denoted to contain 15000 cells; (iv) slides with 18-24 cells per HPF were denoted to contain 20000 cells; (v) slides with 25-34 cells per HPF were denoted to contain 30000 cells; (vi) slides with 35-44 cells per HPF were denoted to contain 40000 cells, etc. Accordingly, the values of total cell count used were: $1000,2000,3000,4000,5000,10000,15000,20000,30000$, 40000 , and so on.
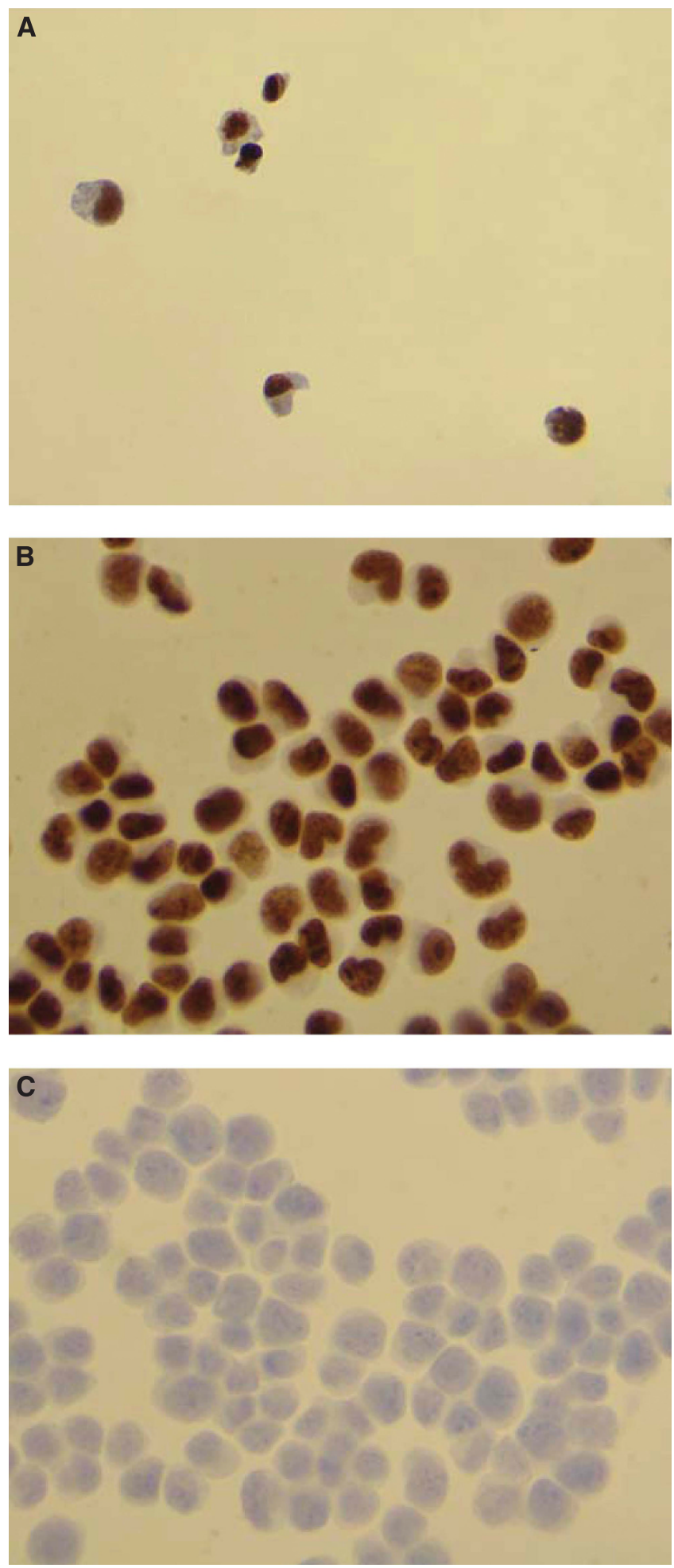

Figure I Representative images from ICC staining. Expression of MCM2 (brown) in cells from the urine of a patient with bladder cancer $(\mathbf{A})$ and in the bladder cancer cell line EJ28 (B). Negative control EJ28 cells stained with non-immune mouse immunoglobulin are shown in $(\mathbf{C})$

Counting of MCM-2-positive nuclei was done in a similar way, providing the total MCM-2 count was greater than 1000, that is, at least one positive nucleus per HPF. For slides with fewer positive nuclei, half of the entire monolayer was examined and the count was then doubled to indicate the number of cells per monolayer 
(slide). This value was then rounded to the nearest 100 cells. If there were fewer than 50 cells in half of the monolayer then the whole monolayer was examined and all positive nuclei counted.

All counting procedures described above were established in the initial studies at Aberdeen. An identical procedure was carried out in Manchester Royal Infirmary for the validation study.

\section{Quality assurance}

In Aberdeen three members of the research team (BR, MM and JN) reviewed the clinical and laboratory data for four groups of participants, namely: randomly selected participants from the $\mathrm{GH}$ and CS groups $(n=20)$; patients with histologically proven bladder cancer $(n=34)$; patients whose outcomes were identified as inconclusive $(n=50)$; and all normal controls $(n=50)$. The essential data checked for accuracy were: participant number, date of birth, cohort, tumour diagnosis including stage and grade, MCM-2 ICC result and cytology result. The overall accuracy ranged from $96-100 \%$.

For the Cambridge study similar quality assurance was carried out in the cytopathology laboratory at Addenbrooke's Hospital, at Quest Laboratories (for ICC) and by two independent cytopathologists at Manchester Royal Infirmary (for slide assessment).

\section{Statistical analysis}

The principal analysis was designed to assess the sensitivity and specificity of MCM-2 cell count for detecting bladder cancer diagnosed cystoscopy and biopsy. Analyses were carried out separately for $\mathrm{GH}$ and $\mathrm{CS}$ patients at each centre. In the initial study in Aberdeen, this was done for different thresholds of total urothelial cell numbers, as well as numbers of MCM-2-positive cells (using 10, 30, 50, 100, 200 and 400 positive cells). Confidence intervals for sensitivity and specificity were calculated to indicate error limits for full population estimation. In addition, for the initial study (Aberdeen) receiver operating characteristics (ROC) curves were plotted and used to determine an optimal intermediate threshold that balanced levels of sensitivity and specificity. For comparison, sensitivity and specificity analyses were also performed using results from routine urine cytology, or from the combination of MCM-2 and cytology. The values were compared with those of MCM-2 ICC alone using the binomial proportions test.

\section{RESULTS}

\section{Initial study (Aberdeen)}

In order to establish thresholds at which MCM-2 would be considered positive, sensitivity and specificity for bladder cancer were calculated using a range of cutoff points based on numbers of MCM-2-positive cells per slide, as well as the total number of urothelial cells present.

Receiver operating characteristics curves were generated from different MCM-2 threshold values, using a minimum total cell count of 5000 to define an adequate sample (Figure 2). The full list of coordinates is provided in the Supplementary Data (Supplementary Tables 1A and 1B). The total number of patients with adequate samples for MCM-2 ICC was 313 (Table 1). For these patients, there were 21 cases of bladder cancer in the GH group (17.9\% of the adequate samples), $5(4.5 \%)$ in the CS group and none in the $\mathrm{MH}$ group. Of the $\mathrm{GH}$ and $\mathrm{CS}$ samples, 230 were adequate for cytology, while 231 were adequate for the combined MCM-2 ICC/cytology test (Table 1).

For the GH samples that were adequate for MCM-2 ICC $(n=117)$, the area under the ROC curve was 0.820 , being different from the random 0.5 level with significance $P<0.0005$. The best compromise cutoff set at an MCM-2 count of 50 or more as a positive. This yielded a sensitivity value of $85.7 \%$ (95\% CI $(63.7$, $97.0)$ ) and a specificity value of $52.1 \%$ (95\% CI $(41.6,62.4)$ ) (Figure 2). Using this threshold, the sensitivity of MCM-2 testing increased with bladder cancer grade, being $75 \%$ for grade $1,80 \%$ for grade 2 and $100 \%$ for grade 3 , although it should be noted that numbers in each category were small (Supplementary Table 2). Sensitivity for disease stage was $83 \%$ for pTa, $100 \%$ for pT 1 and $67 \%$ for pT2 (Supplementary Table 2).

The sensitivity of urine cytology in the same GH group (treating 'indeterminate' as no diagnosis), was less than that of MCM-2 ICC, at $71.4 \%(95 \%$ CI $(47.8,88.7))$. However, urine cytology produced a greater specificity, of $88.5 \%$ (95\% CI $(80.4,94.10)),(P<0.005)$ (Table 1). Sensitivity and specificity values for the combined test (requiring positivity for MCM-2 ICC or cytology) were similar to those for MCM-2 ICC alone (Table 1).

For the CS samples that were adequate for MCM-2 ICC $(n=112)$, the area under the ROC curve was 0.821 , which was significantly different from the random $0.5(P=0.015)$. The best compromise cutoff set an MCM-2 count of 200 or more as a positive. This gave a specificity of $79.4 \%(95 \%$ CI $(70.5,86.6))$ and a sensitivity of $60 \%(95 \%$ CI $(14.7,94.7))$. Using this threshold, the sensitivity of MCM-2 testing increased with bladder cancer grade (being $50 \%$ for grade 2 and $100 \%$ for grade 3 ) and stage $(50 \%$ for $\mathrm{pTa}$, and $100 \%$ for $\mathrm{pT} 2$ ), although numbers in each category were small (Supplementary Table 2).

The specificity of cytology in the same CS group was marginally less than that of MCM-2 ICC, at $72.2 \%$ (95\% CI $(62.8,80.4)$ ), although sensitivity of cytology was markedly lower, at $40 \%(95 \%$ CI $(5.3,85.3)$ ) (Table 1). Sensitivity and specificity values for the combined test were similar to those for MCM-2 ICC alone (Table 1).

\section{Validation study (Cambridge)}

In the validation study, we tested the optimal thresholds of total cell number and number of MCM-2-positive cells that were determined from the initial study. The total number of patients with adequate samples for MCM-2 ICC was 184 (Table 2). For these patients, there were 16 cases of bladder cancer in the GH group (24.2\% of the adequate samples), 19 (21.6\%) in the CS group and none in the $\mathrm{MH}$ group. Of the $\mathrm{GH}$ and $\mathrm{CS}$ samples, 154 were adequate for cytology, while 155 were adequate for the combined MCM-2 ICC/cytology test (Table 2).

For the GH samples that were adequate for MCM-2 ICC $(n=66)$, applying the cutoff of 50 or more MCM-2-positive cells yielded a sensitivity of $81.3 \%$ (95\% CI $(54.4,96.0)$ ), a negative-predictive value (NPV) of $92.7 \%$ and a specificity of $76.0 \%$ (95\% CI $(61.8$, 86.9). Sensitivities were $66.7 \%$ for grade $1,75 \%$ for grade 2 and $87.5 \%$ for grade 3 disease, $100 \%$ for CIS; and $80 \%$ for pTa and $100 \%$ for pT1 tumours (Supplementary Table 3), although numbers in each category were small.

The sensitivity of urine cytology in the same GH group (treating 'indeterminate' as no diagnosis), was lower, at 62.5\% (95\% CI $(35.4,84.8))$, although the difference was not significant $(P=0.433)$. The specificity of urine cytology was similar to that of MCM-2 ICC, at 75.5\% (95\% CI $(61.1,86.7))(P=0.95)$ (Table 2). Sensitivity and specificity values for the combined test (requiring positivity for MCM-2 ICC or cytology) were similar to those for MCM-2 ICC alone (Table 2).

For the CS samples that were adequate for MCM-2 ICC $(n=88)$, applying the cutoff of 200 or more MCM-2-positive cells gave a specificity of $89.9 \%((95 \%$ CI $(80.2,95.8))$, a sensitivity of $63.2 \%$ (95\% CI $(38.4,83.7)$ ) and a NPV of $89.9 \%$. Sensitivities were $42.9 \%$ for grade $1,50 \%$ for grade 2 and $100 \%$ for grade 3 disease; and $56.3 \%$ for pTa and $100 \%$ for pT4 tumours, although numbers in each category were small (Supplementary Table 3).

The specificity of cytology in the same CS group was significantly less than that of MCM-2 ICC, at $77.9 \%(95 \%$ CI 

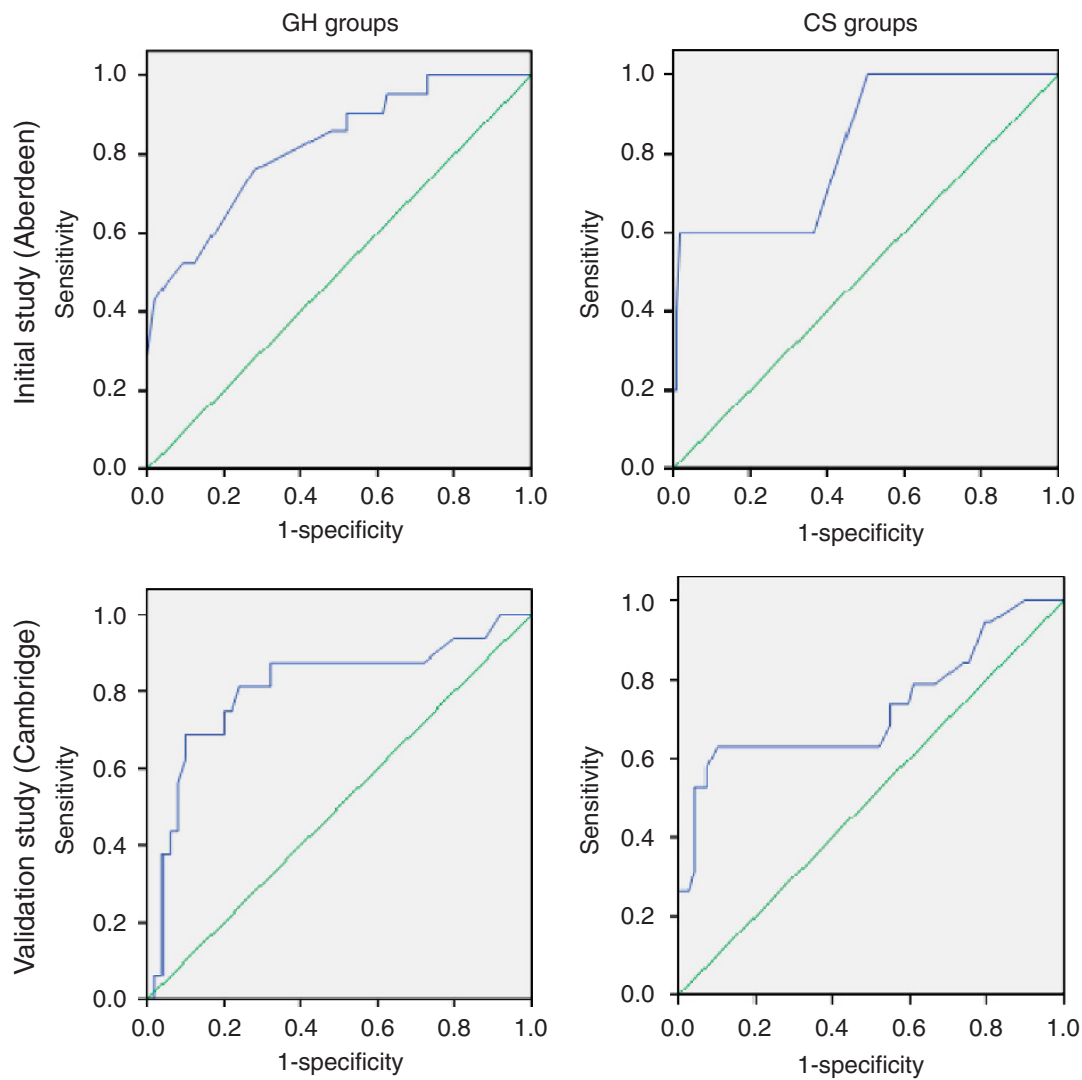

Figure 2 Receiver operator characteristic curve analysis. The top row shows data for the initial study, while the bottom row shows data for the validation study. The GH groups are shown in the left hand column, while the CS groups are in the right hand column. In all graphs, diagonal segments are produced by ties.

$(66.2,87.1))(P=0.05)$. The sensitivity of cytology was also less than that of MCM-2 ICC, at 55.0\% (95\% CI $(31.5,76.9)$ ) (Table 2). Sensitivity and specificity values for the combined test were similar to those for MCM-2 ICC alone (Table 2).

To extend the ROC analysis performed for the Aberdeen data, ROC curves were also drawn for the MCM-2 ICC results from the Cambridge study (Figure 2). For the GH results, the area under the curve was 0.810 , being different from the random 0.5 level with significance $P<0.0005$. The best compromise cutoff was again at 50 MCM-2-positive cells. Similarly, for the CS data the area under the curve was 0.728 , being different from the random 0.5 level with significance 0.002 . The best compromise cutoff was again at 200 MCM-2-positive cells. The full list of coordinates is provided in Supplementary Tables $1 \mathrm{C}$ and $1 \mathrm{D}$, together with the two-way tables for each cutoff point for the GH and CS groups.

\section{DISCUSSION}

Widespread population screening for bladder cancer is not feasible or cost effective. However, focussing on individuals at high risk, such as those with exposure to known carcinogens (cigarette smoke, cyclophosphamide, pelvic radiation and those working in the dye and leather industries), could be worthwhile. Flexible cystoscopy is an integral part of the diagnosis and surveillance of bladder cancer. An accurate biomarker may have the potential to complement, delay or even replace cystoscopy in the monitoring and diagnosis of patients with bladder cancer. Similarly, tumour markers could also complement or replace urine cytology. In the present study, we focussed on assessing the suitability of MCM-2
ICC for detecting bladder cancer in the largest sample set analysed to date, rather than comparing different tests in fewer samples, which would have given less definitive information on the potential of the MCM-2 test.

We studied two main patient groups, in which there are different priorities for the performance of a bladder cancer screening test. In the GH group, high sensitivity is particularly important, while in the CS group high specificity is needed, to avoid unnecessary invasive procedures (Budman et al, 2008). Our initial study showed that a threshold of 50 MCM-2-positive cells was optimal in the GH group. In the validation study, this threshold provided a sensitivity that was superior to urine cytology, with similar specificity. In the CS group there was a different optimal threshold of 200. In the validation study, this threshold provided significantly higher specificity than urine cytology, together with a marginal increase in sensitivity. These benefits are attributable to the improved objectivity offered by MCM-2 ICC, as it is easier for an observer to detect brown-stained nuclei than to evaluate more subtle changes in cell size, shape, nuclear contour, and so on, as required in the analysis of conventional cytology samples. There was minimal benefit from combining MCM-2 ICC and cytology. The numbers of malignant cases overall were too small to allow meaningful logistic regression analysis to compare the performance of MCM-2 ICC alone vs combined MCM-2 ICC and cytology.

The MCM-2 ICC method that we evaluated is a first generation approach, which is likely to evolve in the future. Importantly the ICC slides were evaluated and cell counts determined by human observers. In this setting, optimal discrimination between patients with and without malignancy was provided by a minimal total cell 
count of 5000 per slide, leading to relatively high overall inadequacy rates. The present data warrant development of new generation urine MCM-2 ICC tests, based on image analysis and automated quantification of total cell counts and numbers of immuno-positive cells. This approach is well suited to LBC platforms, which enable automated slide assessment and multiparameter testing. Such objective analysis is likely to provide greater discriminatory power than is provided by human observations, so that lower overall cell numbers (and probably lower MCM-2 thresholds) would be required, thereby increasing sample adequacy. Indeed, given the considerable time and labour required for human observers to assess slides for cell adequacy and MCM-2 numbers, an automated platform for quantifying ICCstained slides is now an important requirement. Such a development would parallel those of liquid-phase assays for bladder cancer, where adequacy requirements improved from 6000 to 1500 MCM-positive cells as test methodology evolved (Stoeber et al, 1999; Stoeber et al, 2002).

The design of the present study only permitted limited comparisons with other approaches to bladder cancer screening. It will be important in future work to perform direct head to head comparisons between MCM-2 ICC, cytology and other biomarker-based tests, such as NMP22, UroVysion and so on (Yutkin et al, 2010). Of principal interest will be the clinical performance (sensitivity, specificity, predictive values, adequacy rates and so on) of the tests, when used singly or in combination. It will also be important to evaluate the practicability of each test and the ease of adoption in clinical laboratories. Minichromosome maintenance protein-2 ICC offers several advantages in this regard. For example, the method of sample collection required is straightforward, being identical to that already in use for obtaining routine urine cytology samples. In addition, MCM-2 ICC signals are suitable for automated detection in future iterations of the test, while the test slides preserve intact cells, allowing morphological information to be derived from the haematoxylin counterstain.

We conclude that MCM-2 ICC offers potential for accurate detection of bladder cancer, in both GH and CS patient groups. The test is well suited to automation and further iterations are likely to improve sample adequacy, throughput and clinical performance, either in isolation or in combination with other biomarkers.

Supplementary Information accompanies the paper on British Journal of Cancer website (http://www.nature.com/bjc)

\section{REFERENCES}

Baldwin P, Laskey R, Coleman N (2003) Translational approaches to improving cervical screening. Nat Rev Cancer 3: 217-226

Budman LI, Kassouf W, Steinberg JR (2008) Biomarkers for detection and surveillance of bladder cancer. Can Urol Assoc J 2: 212-221

Chatrath P, Scott IS, Morris LS, Davies RJ, Rushbrook SM, Bird K, Vowler SL, Grant JW, Saeed IT, Howard D, Laskey RA, Coleman N (2003) Aberrant expression of minichromosome maintenance protein2 and Ki67 in laryngeal squamous epithelial lesions. $\mathrm{Br}$ J Cancer 89: 1048-1054

Davies RJ, Freeman A, Morris LS, Bingham S, Dilworth S, Scott I, Laskey RA, Miller R, Coleman N (2002) Analysis of minichromosome maintenance proteins as a novel method for detection of colorectal cancer in stool. Lancet 359: 1917-1919

Freeman A, Morris LS, Mills AD, Stoeber K, Laskey RA, Williams GH, Coleman N (1999) Minichromosome maintenance proteins as biological markers of dysplasia and malignancy. Clin Cancer Res 5: 2121-2132

Gonzalez MA, Tachibana KE, Laskey RA, Coleman N (2005) Control of DNA replication and its potential clinical exploitation. Nat Rev Cancer 5: 135-141

Halling KC, Kipp BR (2008) Bladder cancer detection using FISH (UroVysion assay). Adv Anat Pathol 15: 279-286

Heney NM, Ahmed S, Flanagan MJ, Frable W, Corder MP, Hafermann MD, Hawkins IR (1983) Superficial bladder cancer: progression and recurrence. J Urol 130: 1083-1086

Herman MP, Svatek RS, Lotan Y, Karakiewizc PI, Shariat SF (2008) Urinebased biomarkers for the early detection and surveillance of non-muscle invasive bladder cancer. Minerva Urol Nefrol 60: 217-235

Herr HW (1999) The natural history of a T1 bladder cancer: life-long tumour diathesis. BJU Int 84: 1102-1103

Hwang EC, Choi HS, Jung SI, Kwon DD, Park K, Ryu SB, Use of the NMP22 (2011) BladderChek test in the diagnosis and follow-up of urothelial cancer: a cross-sectional study. Urology 77: 154-159

Karakiewicz PI, Benayoun S, Zippe C, Ludecke G, Boman H, Sanchezcarbayo M, Casella R, Mian C, Friedrich MG, Eissa S, Akaza H, Huland H, Hedelin H, Rupesh R, Miyanaga N, Sagalowsky AI, Marberger MJ, Shariat SF (2006) Institutional variability in the accuracy of urinary cytology for predicting recurrence of transitional cell carcinoma of the bladder. BJU Int 97: 997-1001

Kearsey SE, Labib K (1998) MCM proteins: evolution, properties, and role in DNA replication. Biochem Biophys Acta 1398: 113-136

Kearsey SE, Maiorano D, Holmes EC, Todorov IT (1996) The role of MCM proteins in the cell cycle control of genome duplication. Bioessays 18: $183-190$

Korkolopoulou P, Givalos N, Saetta A, Goudopoulou A, Gakiopoulou H, Thymara I, Thomas-tsagli E, Patsouris E (2005) Minichromosome maintenance proteins 2 and 5 expression in muscle-invasive urothelial

cancer: a multivariate survival study including proliferation markers and cell cycle regulators. Hum Pathol 36: 899-907

Lotan Y, Roehrborn CG (2003) Sensitivity and specificity of commonly available bladder tumor markers $v s$ cytology: results of a comprehensive literature review and meta-analyses. Urology 61: 109-118; discussion 118

Madine MA, Swietlik M, Pelizon C, Romanowski P, Mills AD, Laskey RA (2000) The roles of the MCM, ORC, and Cdc6 proteins in determining the replication competence of chromatin in quiescent cells. J Struct Biol 129: 198-210

Maiorano D, Van Assendelft GB, Kearsey SE (1996) Fission yeast cdc21, a member of the MCM protein family, is required for onset of $S$ phase and is located in the nucleus throughout the cell cycle. $E M B O J$ 15: 861-872

Musahl C, Holthoff HP, Lesch R, Knippers R (1998) Stability of the replicative $\mathrm{Mcm} 3$ protein in proliferating and differentiating human cells. Exp Cell Res 241: 260-264

Pagano F, Bassi P, Galetti TP, Meneghini A, Milani C, Artibani W, Garbeglio A (1991) Results of contemporary radical cystectomy for invasive bladder cancer: a clinicopathological study with an emphasis on the inadequacy of the tumor, nodes and metastases classification. J Urol 145: 45-50

Prout JR GR, Barton BA, Griffin PP, Friedell GH (1992) Treated history of noninvasive grade 1 transitional cell carcinoma. The National Bladder Cancer Group. J Urol 148: 1413-1419

Rodgers M, Nixon J, Hempel S, Aho T, Kelly J, Neal D, Duffy S, Ritchie G, Kleijnen J, Westwood M (2006) Diagnostic tests and algorithms used in the investigation of haematuria: systematic reviews and economic evaluation. Health Technol Assess 10: iii-iv, xi-259

Rubben H, Lutzeyer W, Fischer N, Deutz F, Lagrange W, Giani G (1988) Natural history and treatment of low and high risk superficial bladder tumors. J Urol 139: 283-285

Scarpini C, White V, Muralidhar B, Patterson A, Hickey N, Singh N, Mullerat J, Winslet M, Davies RJ, Phillips ML, Stacey P, Laskey RA, Miller R, Nathan M, Coleman N (2008) Improved screening for anal neoplasia by immunocytochemical detection of minichromosome maintenance proteins. Cancer Epidemiol Biomarkers Prev 17: 2855-2864

Sirieix PS, O'donovan M, Brown J, Save V, Coleman N, Fitzgerald RC (2003) Surface expression of minichromosome maintenance proteins provides a novel method for detecting patients at risk for developing adenocarcinoma in Barrett's esophagus. Clin Cancer Res 9: 2560-2566

Stoeber K, Halsall I, Freeman A, Swinn R, Doble A, Morris L, Coleman N, Bullock N, Laskey RA, Hales CN, Williams GH (1999) Immunoassay for urothelial cancers that detects DNA replication protein $\mathrm{Mcm} 5$ in urine. Lancet 354: 1524-1525

Stoeber K, Swinn R, Prevost AT, De Clive-lowe P, Halsall I, Dilworth SM, Marr J, Turner WH, Bullock N, Doble A, Hales CN, Williams GH (2002) 
Diagnosis of genito-urinary tract cancer by detection of minichromosome maintenance 5 protein in urine sediments. J Natl Cancer Inst 94: 1071-1079

Stoeber K, Tlsty TD, Happerfield L, Thomas GA, Romanov S, Bobrow L, Williams ED, Williams GH (2001) DNA replication licensing and human cell proliferation. J Cell Sci 114: 2027-2041

van der Poel HG, Debruyne FM (2001) Can biological markers replace cystoscopy? An update. Curr Opin Urol 11: 503-509
Williams GH, Romanowski P, Morris L, Madine M, Mills AD, Stoeber K, Marr J, Laskey RA, Coleman N (1998) Improved cervical smear assessment using antibodies against proteins that regulate DNA replication. Proc Natl Acad Sci USA 95: 14932-14937

Yutkin V, Nisman B, Pode D (2010) Can urinary biomarkers replace cystoscopic examination in bladder cancer surveillance? Expert Rev Anticancer Ther 10: 787-790

This work is published under the standard license to publish agreement. After 12 months the work will become freely available and the license terms will switch to a Creative Commons Attribution-NonCommercial-Share Alike 3.0 Unported License. 